\title{
Experimental characterization and numerical determination of the rigidity of a Binder Magnetic synchronous belt transmission type AT10
}

Merghache Sidi Mohammed ( $\nabla$ sidimohamedmerghache@gmail.com )

University Center of Tissemsilt

Merghache Sidi Mohammed

University Center of Tissemsilt

Hamdi Amine

University Center of Tissemsilt

\section{Research Article}

Keywords: Synchronous belt, Measured, Rigidity, Effort, Displacement sensor, Stiffness

Posted Date: April 12th, 2021

DOI: https://doi.org/10.21203/rs.3.rs-389844/v1

License: (c) (i) This work is licensed under a Creative Commons Attribution 4.0 International License.

Read Full License 


\title{
Experimental characterization and numerical determination of the rigidity of a Binder Magnetic synchronous belt transmission
}

\author{
type AT10 \\ Merghache Sidi Mohammed $^{1 *}$, Hamdi Amine ${ }^{1}$ \\ ${ }^{1}$ Laboratory of Mechanical Engineering, Materials and Structures, University Center of Tissemsilt - \\ 38000 Tissemsilt-Algeria.
}

\begin{abstract}
Given the important role of synchronous belts in the functioning of mechanisms, they are the subject of numerous studies and researches in order to define them more and more finely. Their mechanical characteristics influence the behavior in operation of the mechanisms that they entail. Also, the measurement of the characteristics of the longitudinal stiffness of the belt and the stiffness of the teeth is necessary to better control their behavior. In addition, these parameters constitute input data for models of lifetime and dynamic behavior of synchronous transmissions. An approach for the determination of longitudinal stiffness is presented. We have demonstrated a study comparing the measurement of the rigidity of a toothed belt by two methods. This is to qualify the first method of measurement through experimentation. And the second measurement method using the simulation of this toothed belt by SOLIDWORKS software.
\end{abstract}

Keywords: Synchronous belt; Measured; Rigidity; Effort; Displacement sensor; Stiffness. 


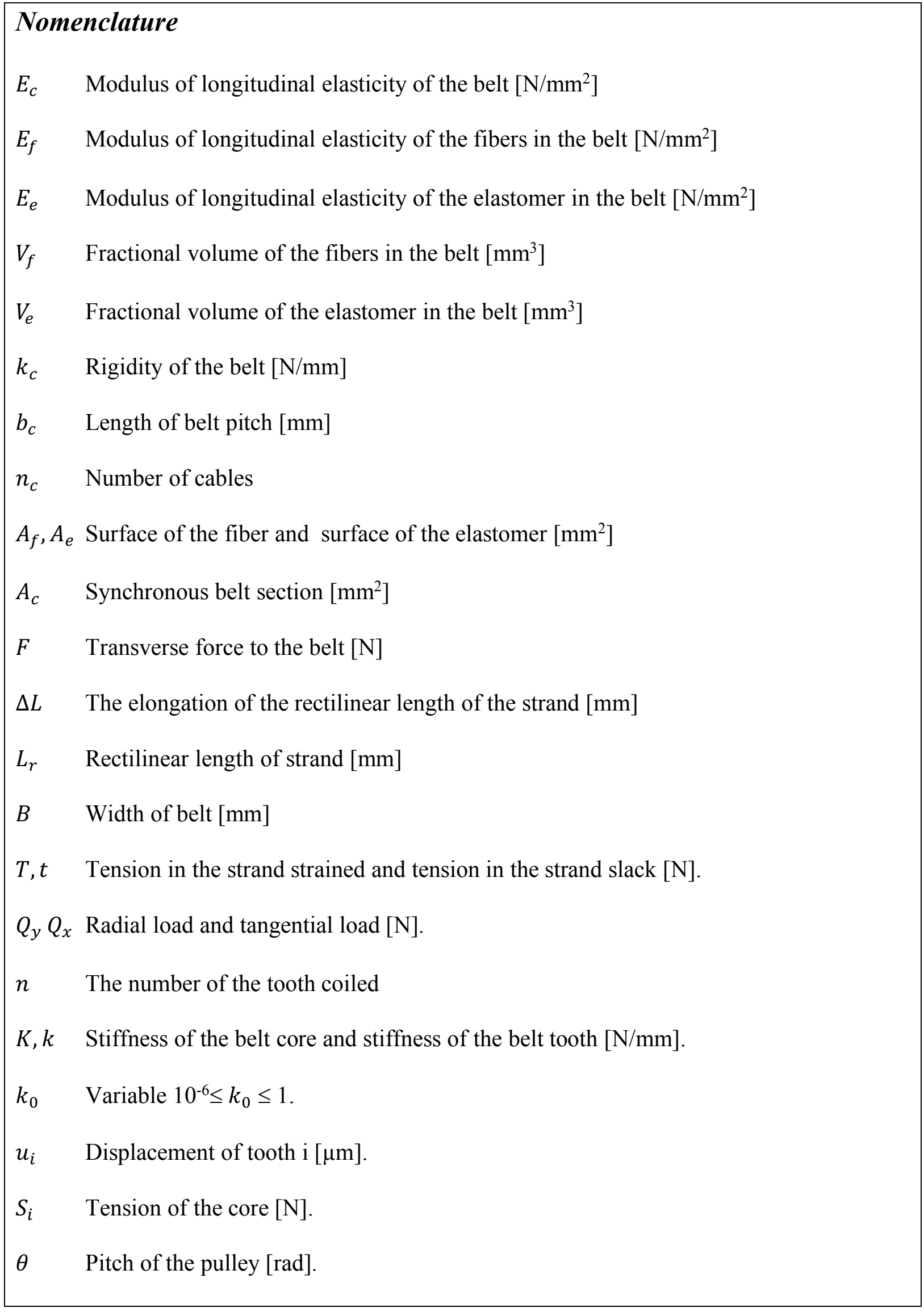




\section{Introduction}

The toothed belts in Fig. 1 are flat belts, the inner face of which is provided with transverse teeth which mesh with the notches of a notched pulley. These belts are used when it is desired to eliminate the slippage between the belts and the pulleys in order to obtain a synchronized transmission that is to say so that the speed ratio remains constant and precise. These are elements of machines which essentially serve to transmit forces, rotational movements and which have many advantages including: transmission of the forces without slip with a good angular accuracy (so-called synchronous transmission), operation at high speeds Exceed 50m / $\mathrm{s}$ and a transmission between distant trees up to several meters and a good power-to-weight ratio. However, they present some disadvantages, particularly a mark of robustness (very limited lifetime) and a problem of reliability of operation. However, due to their mechanical advantages, synchronous belts are a very useful transmission element in industry [1.9].

Much research began 70 years ago in both theoretical and experimental directions to define and understand the behavior of synchronous belts and thus optimize the lifetime. This research has really contributed to the scientific evolution of the problem and has succeeded in clarifying certain points, but much remains to be done in view of the published results, namely:

- The phenomena carried out are generally global (rigidity, distribution of load, etc ...).

- The phenomena involved at the level of the contact-belt (contact problem) have not been visualized or clearly demonstrated (frictional forces, variation of geometry and its influence on friction conditions, understanding of sliding phenomena).

- The geometry considered in finite element models is defined very schematically using simplified boundary data to obtain orders of magnitude of stress distribution. The patterns generally take into account the stiffness of the teeth, the stiffness of the core and the tension of the soft strand and the tensioned strand. 
In statics, numerous studies have been carried out in the field of tooth behavior and the distribution of the load on the teeth. Gerbert [2] to present a direct method for measuring the displacement of a toothed belt tooth. The displacement of the tooth is measured by means of a comparator. The belt is toothless on both sides of the chosen tooth. The friction of the belt on the winding arc is taken into account to calculate the stiffness of the tooth. The measurement of the stiffness of the core is done on a conventional traction machine. Childs [3] demonstrated the relationship between the rigidity of the synchronous belt and its constituents using fractional volume theory and show that the elastic modulus of the belt is given by:

$$
E_{c}=E_{f} \cdot V_{f}+E_{e} \cdot V_{e}
$$

Using the Hooke's law, we have the following relation:

$$
k_{c} b_{c}=n_{c} \cdot E_{f} \cdot A_{f}+E_{e} \cdot A_{e}
$$

Where, $E_{c}$ is modulus of longitudinal elasticity of the belt, $E_{f}$ is modulus of longitudinal elasticity of the fibers in the belt, $E_{e}$ is modulus of longitudinal elasticity of the elastomer in the belt, $V_{f}$ is fractional volume of the fibers in the belt, $V_{e}$ is fractional volume of the elastomer in the belt, $k_{c}$ is rigidity of the belt, $b_{c}$ is length of belt pitch, $n_{c}$ is number of cables, $A_{f}$ is surface of the fiber and $A_{e}$ is surface of the elastomer .

In 1993, Childs [4] also developed a new method for measuring the stiffness of teeth. Four pulleys are applied with lateral force to two teeth placed back to back. Dalgarno [5] also assert that the contribution to the rigidity of the elastomer is negligible compared to that of the fiber and that the rigidity of the belt is determined solely by the tensioning element. Thus the relationship becomes:

$$
k_{c}=\frac{n_{c} \cdot E_{f} \cdot A_{f}}{b_{c}}
$$


Otherwise, after extensive laboratory tests, Wallin [6] shows that the dynamic elongation of the synchronous belt and its stiffness can be quantified by the product of the elastic modulus E, by the cross section of the belt:

$$
E_{c}=\frac{F \cdot L_{r}}{A_{c} \cdot \Delta L}
$$

Where, $A_{c}$ is synchronous belt section, $F$ is transverse force to the belt, $\Delta L$ is the elongation of the rectilinear length of the strand and $L_{r}$ is rectilinear length of strand.

In 1990, Debbabi [7] attempted to establish a law of dynamic modulus evolution according to various factors but had to give up. The dynamic modulus is sensitive mainly to the frequency and amplitude of the excitation, but above all to the internal temperature of the polymer. The temperature factor will not be taken into account either in this article. Dancé [8] developed two methods, the first to measure the stiffness of the belt core on a conventional traction machine. The second method for obtaining the displacement of a belt tooth as a function of the applied load differs from the previous methods of direct measurement. Indeed, the experimenter notices that the displacement of a loaded tooth depends on the way it is housed in the hollow of the pulley. This method is based on a feeler which measures the displacement of the first tooth, with a variable number of belt teeth in contact with the pulley. This method is more precise, more reliable, and taking into account the previous methods, from a point of view measurement of the stiffness of a belt tooth.

However, that Atouf [9] obtains very weakly non-linear core stiffness by a speckle measurement over two steps of HTD belt. The stiffness will be considered constant throughout the belt although the wiring is not homogeneous. Dynamic stiffening will not be considered in this article. Monternont [10] described a module whose task is to simplify considerably the computation of equation, of motion. The local appearance at the winding arcs is supported at the 3rd module. The macroscopic aspect is the subject of this 3 rd module. 
Strictly, the model has three degrees of freedom of longitudinal translation by belt pitch (two at the core and one at the level of the tooth). This plethora of variables (the strap used for this study has 250 steps) leads to an over-dimensioning of the system in relation to the needs.

BINDER transmission belts are the subject of numerous studies and research in order to optimize their behavior and in particular their lifetime. Several laboratories have been working for several years on the numerical modeling of the static and dynamic behavior of belt transmission type BINDER MAGNETIC. This article is divided into two parts. In the first part, we have shown a comparison study of the measurement of the rigidity of the core of a toothed belt by two methods. The first method of measurement is to be described as experimental. And the second measurement method using the simulation of this toothed belt by SOLIDWORKS software. On the other hand, the second part develops an experimental measurement method for the characterization of the stiffness of an AT10 belt tooth as a function of its tangential and radial load.

This document is organized as follows. In Section 2 is devoted to an experimental and numerical study of the measurement of the stiffness of the blade of the two AT10 belts of width $16 \mathrm{~mm}$ and $20 \mathrm{~mm}$. Section 3 presents an experimental method for measuring tooth stiffness characterization of two AT10 belts of width $16 \mathrm{~mm}$ and $20 \mathrm{~mm}$ as a function of its tangential and radial load. Section 4 presents the measurement results and simulations, and a discussion in view of the previous studies. The conclusion is drawn in Section 5.

\section{Structure of AT10 type timing belts}

A timing belt is an endless belt in the longitudinal direction with rectangular cross-sections and transverse teeth disposed either on one face (inside or outside) of the belt or on both sides. In a transverse section a series of string sections can be seen. They allow the loads to be transmitted and define a primitive line all along the belt. They are wound in pairs and the torsion helices of two successive strings are opposite. 
In general the strings are made of fiberglass, polyester, Kevlar and steel. The timing belts are equipped with standard galvanized steel cables. Thanks to these cables, the belts retain their stability of length (Fig. 2 and Table.1). However, like any metal, the steel deforms under the force following Hooke's law [11.12]. This law describes the deformations under stress in the phase of elasticity. The elongation of the belt will be proportional to the stress in the strand.

\section{Measurement of the stiffness of the blade of a toothed belt}

\subsection{Principle of measurement}

The stiffness of a belt step is measured by a static tensile test according to the following procedure (Fig.3):

- The belt is placed between two jaws, one fixed connected to the frame and the other mobile connected to the pneumatic load cylinder,

- Two studs $a$ and $b$ are glued at thirty pitch intervals on the back of the belt. The vertical displacement of each of the pads $\left(X_{a}\right.$ et $\left.X_{b}\right)$ is measured by means of two micrometric sensors,

- The belt is subjected to a tensile force in steps with a load varying in a range from 0 to 100 $\mathrm{kg}$,

- After each loading stage, the sensors are reset. This operation is carried out directly on the micrometric sensors using screws. This step is necessary to measure the deformation due separately to each of the load stages. The total displacements are obtained by the sum of all these measured displacements. The elongation of the pitch strand is thus obtained by the difference between the total displacement of the sensors mounted at each end,

- The stiffness of the 30 pitch strand is calculated by dividing the total force applied by the measured elongation, 
The stiffness of a belt pitch is finally obtained by multiplying by 30 the one of the pitch strand. Indeed, the toothed belt is assimilated to a series of springs mounted in series, each rigidity then representing a pitch:

$$
\frac{1}{K_{e q}}=\sum \frac{1}{k_{i}}=\frac{n}{k_{i}}
$$

From where :

$$
k_{i}=30 * K_{e q}
$$

\subsection{Résults}

The results of the various series of tests are summarized in Table 2 and Table 3, illustrated in Fig. 4:

It can be seen that the two curves check the belt traction curve, ie for the two AT10 belts (width 16 and $20 \mathrm{~mm}$ ), the elongation of a 30-pitch strand increases with the increase Of the tensile force (slope between $16^{\circ}$ and $18^{\circ}$ ). It is also noted that as the load increases the stiffness increases and this is due to the elongation of the cables of the belt. The width of the belt plays an essential role in increasing the rigidity of the core. The $20 \mathrm{~mm}$ wide belt is stiffer than the $16 \mathrm{~mm}$ belt. The stiffness of the belt is determined on the basis of test results see table 4 .

\subsection{Simulation of the mechanical behavior of the belt}

In static analysis, the finite element model of the belt tooth is generated by importing the geometric (solid) model of the structure modeled under SolidWorks. We define the properties of the materials, the constraints (imposed displacements), the necessary loadings and the type of mesh. Thus, the global mesh of the system is generated by tetrahedral quadratic 3D 
elements of sizes $41.634 \mathrm{~mm}$. The system is discretized in 24384 elements linked to 35595 nodes.

\subsection{Results}

Fig. 5 and Fig. 6 show the results of simulation of the tooth of the two belts conducted in this study.

It is found that the elongations and deformations of the pitches of the two belts AT10 increase linearly when the tensile force increases, see Fig. 7.

\subsection{Results and discussion}

It is observed that the two curves check the traction curve for the two AT10 belts (width 16 and $20 \mathrm{~mm}$ ), the elongation of a 30-step strand increases with increasing tensile force. It is also noted that as the load increases, the stiffness increases and this is due to the elongation of the belts of the belt. The $20 \mathrm{~mm}$ wide belt is stiffer than the $16 \mathrm{~mm}$ belt.

It is found that the stiffness measured at a small deviation from the simulated stiffness for the two AT10 belts (width $16 \mathrm{~mm}$ and width $20 \mathrm{~mm}$ ) see Table 5. And this is due to the experimental condition such as the errors related to the pneumatic cylinder loading and the errors of the elongation measurement sensors.

\section{Principle for measuring the stiffness of the belt tooth}

\subsection{Theoretical aspect}

The objective of this method is to obtain the law $Q_{x}\left(u, Q_{y}\right)$, this law is obtained at the end of several series of measurement points $\left(T, u_{i}\right)$ within each case a rolled tooth number $n$ As well as the tension $t$ in the soft strand. The charge $Q_{x}$ on the $\mathrm{i}^{\text {th }}$ tooth of the wound arc comprising $n$ teeth is obtained from the Gerbert equation [9]:

$Q_{x} \cdot \operatorname{sh}\left(k_{0} \cdot n\right)=t \cdot\left[\operatorname{sh}\left(k_{0} \cdot(i-1)\right)-\operatorname{sh}\left(k_{0} \cdot i\right)\right]+T .\left[\operatorname{sh}\left(k_{0} \cdot(n+1 i)\right) \operatorname{sh}\left(k_{0} \cdot(n-i)\right)\right]$ 
With

$$
k_{0}=\sqrt{K / k}
$$

Where, $T$ is tension in the strand strained, $t$ is Tension in the strand slack, $Q_{Y}$ is radial load, $Q_{x}$ is tangential load, $n$ is the number of the tooth coiled, $K$ is of the belt core, $k$ is stiffness of the belt tooth and $k_{0}$ is variable.

According to this equation, only $Q_{x}$ and stiffness of tooth $K$ are unknown. These two unknowns require a second equation:

$$
Q_{x}=K \cdot u_{i}
$$

The calculation of the radial load $Q_{y_{i}}$, on the tooth i require the calculation of the voltages in the core $S_{i}$ by the following equation:

$$
S_{i} \cdot \operatorname{sh}\left(k_{0} \cdot n\right)=t \cdot \operatorname{sh}\left(k_{0} \cdot i\right)+T \cdot \operatorname{sh}\left(k_{0} \cdot(n-i)\right)
$$

So

$$
Q_{y_{i}}=\left(\frac{S_{i}+s_{i+1}}{2}\right) \cdot \sin \left(\frac{\theta}{2}\right)
$$

Where, $u_{i}$ is displacement of tooth $\mathrm{i}, S_{i}$ is tension of the core and $\theta$ is pitch of the pulley.

\subsection{Practical aspects}

A belt tooth traction bench (Fig. 8) has been developed in order to accurately and reliably, ie repetitively, measure the deformation of a tooth. The belt wraps around a fixed pinion whose immobility is verified by a micrometric comparator. The strap is attached to two places by two jaws which allow it to continue freely its way. Thus, it is not necessary to destroy the belt. The soft strand is free and is fixed at a weight of known mass which is varied $(5,10$ and $15 \mathrm{~kg})[4]$. It wraps around a pebble. The tension in the soft strand is thus known 
and remains permanently constant. In addition, the roller can move to increase or decrease the winding arc. The tension in the tensioned strand is measured by a dynamometer. The movement of two teeth is measured using a probe and a small die attached to the back of the belt. The two simultaneous measurements increase the quality of the evaluation of the displacement of a tooth under a given load. These two teeth should be placed in the middle of the wrapped arc in order to eliminate the bending effects due to the stiffness of the bending of the belt. The measurement of the displacement of the teeth is done by varying three parameters:

- The tension $\mathrm{t}$ in the soft strand by modifying the mass.

- The tension $\mathrm{T}$ in tensioned strand, which varies from the tension $\mathrm{t}$ to the phenomenon of the jump of the tooth.

- The number of teeth $\mathrm{n}$ in engagement varying with the roller.

\subsection{Results}

The results of the various series of tests are illustrated in Fig.9, Fig.10, Fig.11, Fig.12, Fig.13 and Fig.14:

It is noted that the tangential load increases with the increase of the load and also increases with the increase of displacement, but for the tangential stiffness it is the inverse that is to say it decreases with the decrease of the load And the increase in displacement.

\subsection{Results and discussion}

The Fig. 15 and Fig. 16 shows the variation in the tangential stiffness and tangential load $Q_{x}$ of a tooth according to the displacement $\mathrm{u}$ of the tooth and the tangential load. 
The analysis of Fig.15-a and Fig.15-b allows us to deduce that when the radial load $Q_{y}$ increases, there is an increase in the stiffness of the tooth. It is also observed that this tangential stiffness decreases when the displacement of the tooth $\mathrm{u}$ increases. The results illustrated by Fig.16-a have shown that the tangential load $Q_{x}$ increases with the increase of the radial load $Q_{y}$. It is also notices that this tangential load increases when the displacement of the tooth $\mathrm{u}$ varies from 0 to $450 \mu \mathrm{m}$ and Decreases when this displacement varies from 450 to $750 \mu \mathrm{m}$. On the other hand, it can be seen from Fig.16-b that the tangential load $Q_{x}$ increases when the radial load $Q_{y}$ and the displacement of the tooth $u$ increase.

Fig. 17 shows the variation in the tangential stiffness of the teeth of $16 \mathrm{~mm}$ width and $20 \mathrm{~mm}$ AT10 belt depending on the load and $Q_{y}$ for different tooth displacement values: $\mathrm{u}=0 \mu \mathrm{m}, \mathrm{u}$ $=150 \mu \mathrm{m}$ and $\mathrm{u}=300 \mu \mathrm{m}$.

From Fig. 17 it can be seen that the tangential stiffness of the tooth increases linearly with the increase in the radial load $Q_{y}$ and decreases as the displacement of the tooth increases from 0 to $300 \mu \mathrm{m}$. However, it is observed that the deviation of the tangential stiffness increases from 0 to $4.105 \mathrm{~N} / \mu \mathrm{m}$ when the radial load $Q_{y}$ increases from 0 to $120 \mathrm{~N}$ and at the same time this difference in stiffness increases from 4.105 to $17.105 \mathrm{~N} / \mu \mathrm{m}$ when the displacement $\mathrm{u}$ varies from 0 to $300 \mu \mathrm{m}$ see Table 6 .

Table 6 shows that the ratio of the stiffness of the tooth between the two belts of the widths 16 $\mathrm{mm}$ and $20 \mathrm{~mm}$ remains constant when the radial load $Q_{y}$ increases and decreases when the displacement of the tooth $\mathrm{u}$ increases from 0 to $300 \mu \mathrm{m}$. 


\section{Conclusion}

This study is part of the dynamic determination of the characteristics of AT10 type toothed belts. The studies that we have carried out for the determination of the longitudinal stiffness of the belt and the stiffness of the belt teeth, have confirmed that the geometry of the belts plays an important role in their static and dynamic behavior in service:

- It can be deduced that the longitudinal stiffness of the belt increases when the width thereof increases.

- The tangential tooth stiffness of AT10 type belts increases linearly with increasing radial load Qy and decreases with increasing tooth displacement $u$. This increased displacement is due to the increased tension on both the taut and slack ends.

- The stiffness of the teeth affects the distribution of loads on the pulley.

\section{Acknowledgments}

This research was supported by the Mechanical Engineering, Materials and Structures Laboratory approved in 2020 by Ministerial Order $\mathrm{N}^{\circ} 05$ on 18 February 2020 , a laboratory of excellence at the University Center of Tissemsilt. The support and interest of our sponsors are gratefully acknowledged.

\section{Author information}

\section{- Affiliations}

1. Laboratory of Mechanical Engineering, Materials and Structures, University of Tissemsilt -38000 Tissemsilt-Algeria-[Merghache Sidi Mohammed].

2. Laboratory of Mechanical Engineering, Materials and Structures, University of Tissemsilt -38000 Tissemsilt-Algeria-[Hamdi Amine].

\section{- Corresponding author}

Correspondence to Merghache Sidi Mohammed 


\section{Authors' Contributions}

Merghache Sidi Mohammed was in charge of the whole trial. All authors read and approved

\section{Ethics declarations}

- Conflict of interest

The authors declare that they have no conflict of interest.

- Code availability

Not applicable.

\section{Data Availability}

The data used to support the findings of this study are included within the article. 


\section{References}

[1] J.M. Dance, D.Play, « Geometrical design parameters influence on timing belt load distribution», JSME, Hiroshima 1991, pages (357/362).

[2] G. Gerbert, « Load distribution in timing belts», Journal of mechanical Design (Transactions of the ASME), April. 1978, Volume (100), pages (208/215).

[3] T. Childs, «Tooth loading and life of automotive timing belts», Elsevier 1991, TribologySerie18,pages (341/352).

[4] T.H. Childs, « Characterization of Synchronous Belt Properties », Plastics Rubber and Composites Processing and Applications, 1993, Volume (20). Pages (25/33).

[5] K. Dalgamo, "Synchronous Belt Properties; durablilty and performance », PHD thesis, University of Bradford, 1991, 290 pages.

[6] A. W. Wallin, « Selecting Synchronous Belts for Precise Positioning », Power Transmission Design, 1989.

[7] J.M. Dancé, « Comportement Statique et Cinématique des Transmissions par Courroies Synchrones», thèse de doctorat, 1992, Nº 92 ISAL 0082, INSA de Lyon, 239 pages.

[8] M. Atouf, « Etude du Comportement Mécanique des Dentures Courroies Synchrones : Application aux Courroies de type H.T.D », thèse de doctorat, 1992, $\mathrm{N}^{\circ} 92$ ISAL 0063, INSA de Lyon, 209 pages.

[9] C. Debbabi, « Contribution à l'étude dynamique des Courroies de transmission Soumises aux Irrégularités Cycliques de Vitesse des Moteurs », thèse de doctorat, 1990, Université Pierre et Marie Curie (Paris VI), 182 pages.

[10] Play. D, Merghache. « Determination of Timing belts Performances for Industrial Applications», JSME, International Conference on Motion and Power Transmissions (MPT 2001), Fukuoka (Japon), 2001, page (779/784) 
[11] S. Merghache, A. Ghernaout, « Influence of temperature on the performance toothed belts-binder magnetic », European Scientific Journal, Edition November 2013, volume (9), N³3, pages $(206 / 212)$.

[12] S. Merghache, A. Serrail, «Evaluation de la température sur une transmission par courroie dentée -binder magnetic ", RDM, Edition juin 2013, volume (1), pages $(27 / 33)$.

\section{Highlights}

- The vertical displacement of each of the studs is measured by two micrometric sensors,

- The tension in the taut end is measured by a dynamometer.

- The stiffness's of the web and teeth of a belt are calculated theoretically.

- Experimental determination of the stiffness of the tooth of the AT10 belt. 
Figures

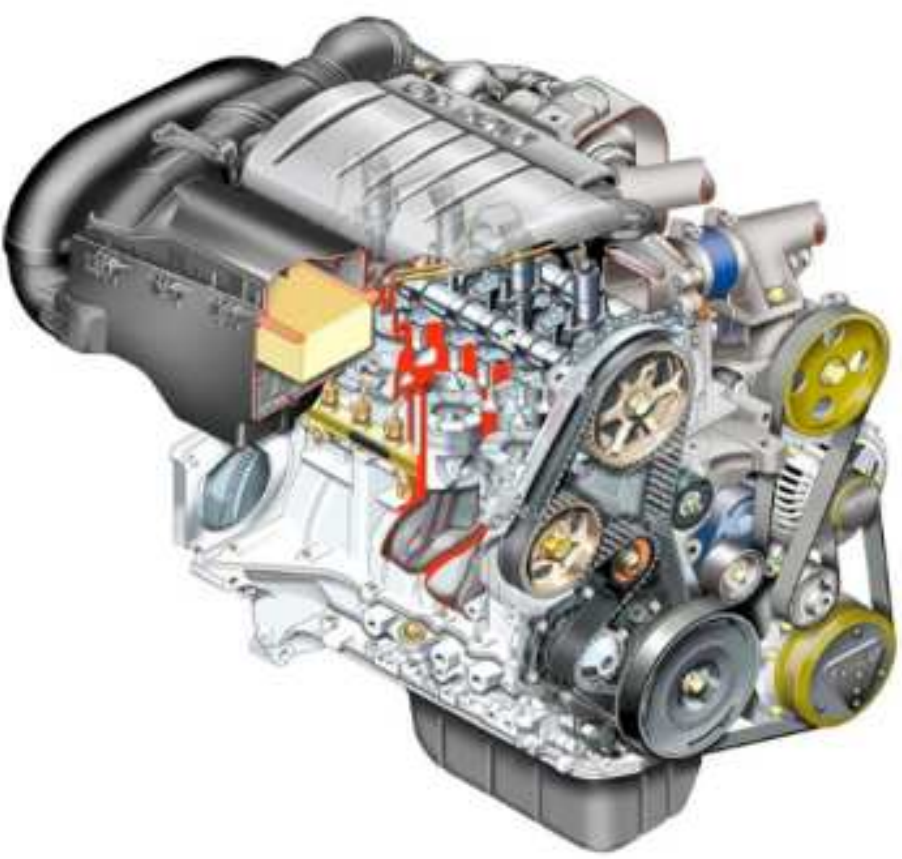

Figure 1

Transmission by a timing belt.

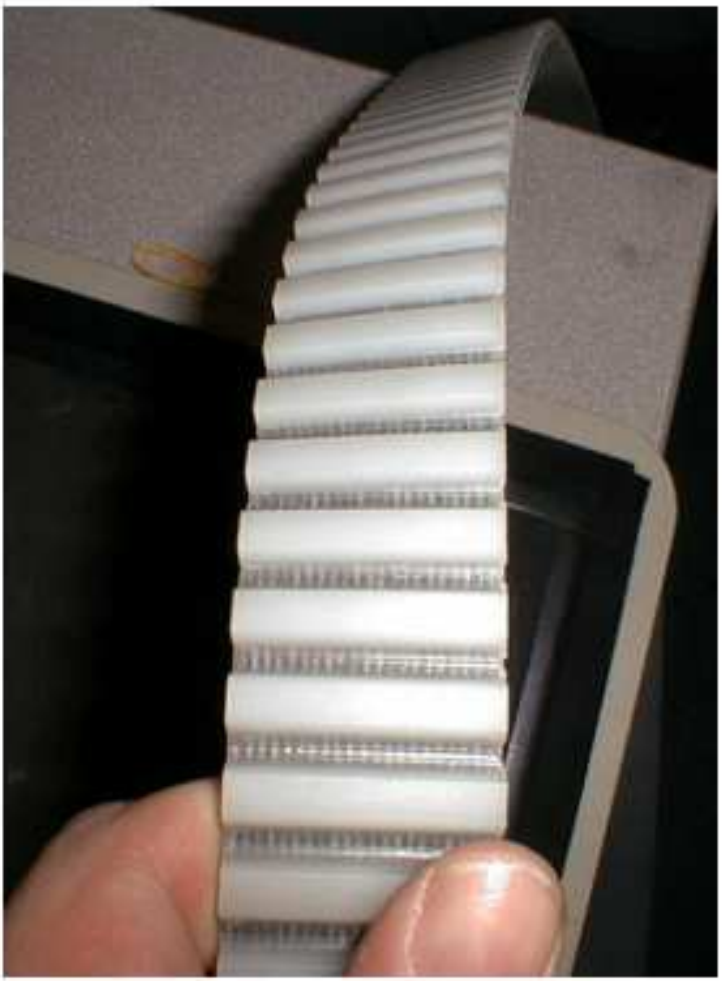

Figure 2 
Structure of a timing belt

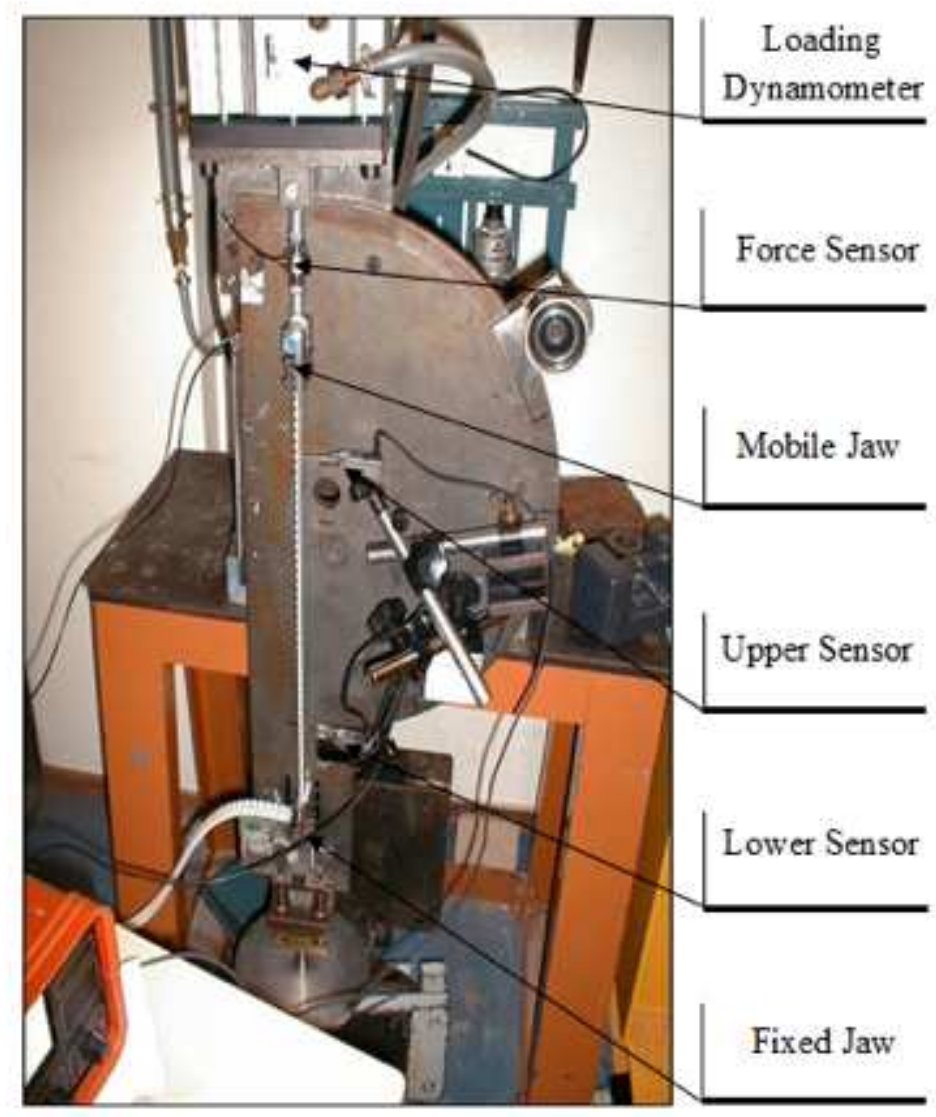

Figure 3

Device for measuring the stiffness of the soul of the belt. 

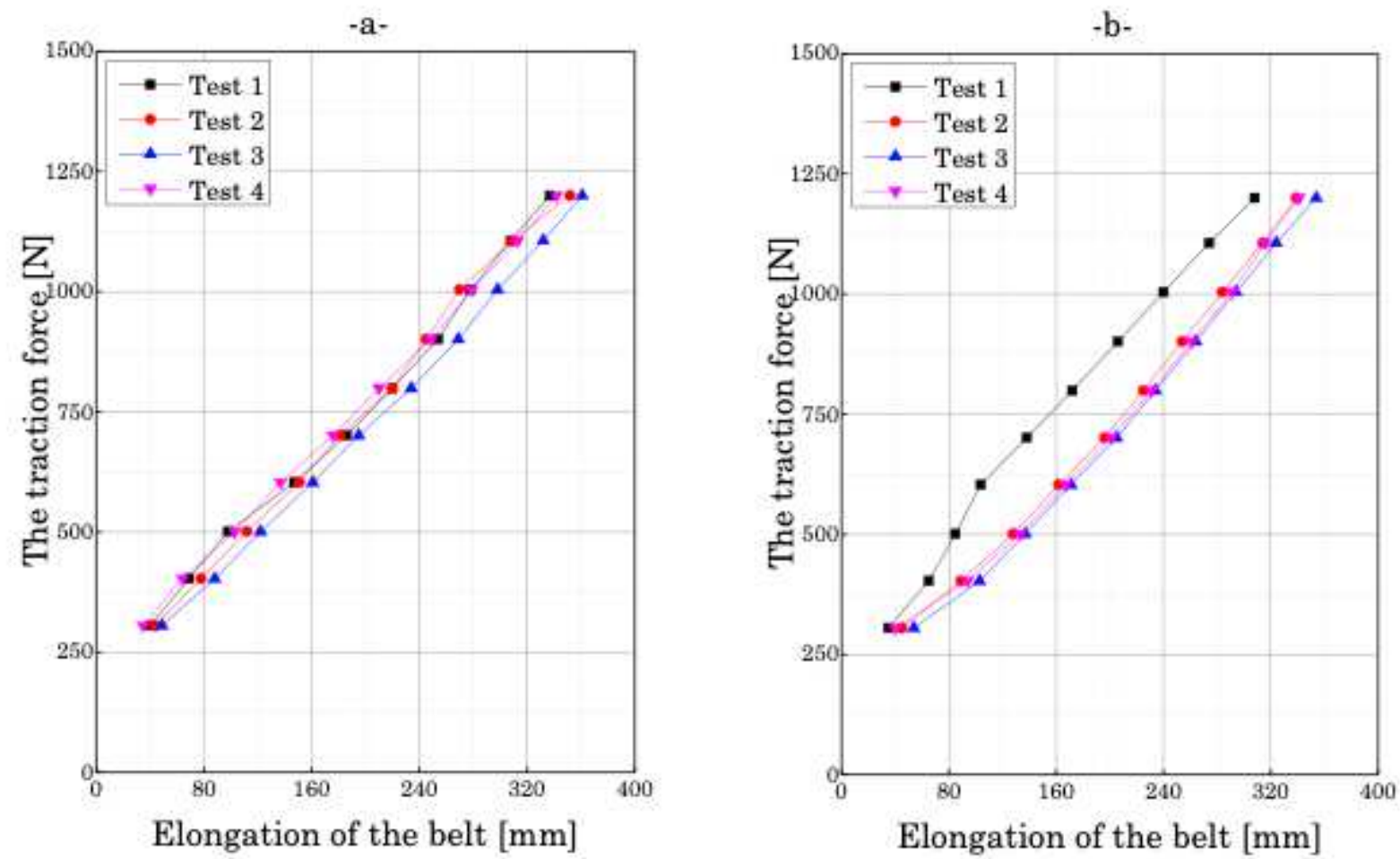

\section{Figure 4}

The experimental variation of the traction effort with respect to the elongation: $a$ - width $16 \mathrm{~mm}, \mathrm{~b}$ - width $20 \mathrm{~mm}$
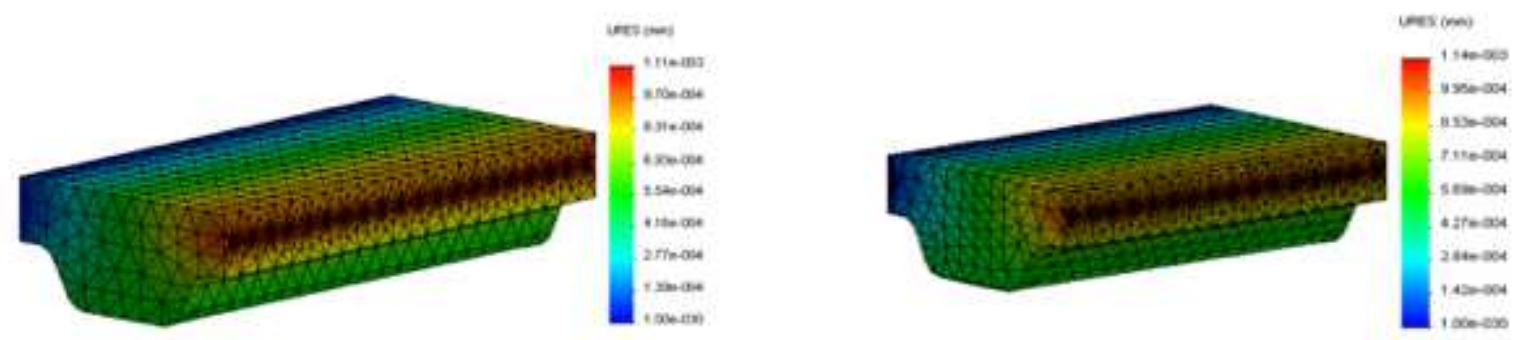

\section{Figure 5}

The displacements of the tooth of a belt AT10 for a tensile force of $100 \mathrm{~N}$ : $\mathrm{a}-\mathrm{B}=20 \mathrm{~mm}, \mathrm{~b}-\mathrm{B}=16 \mathrm{~mm}$.

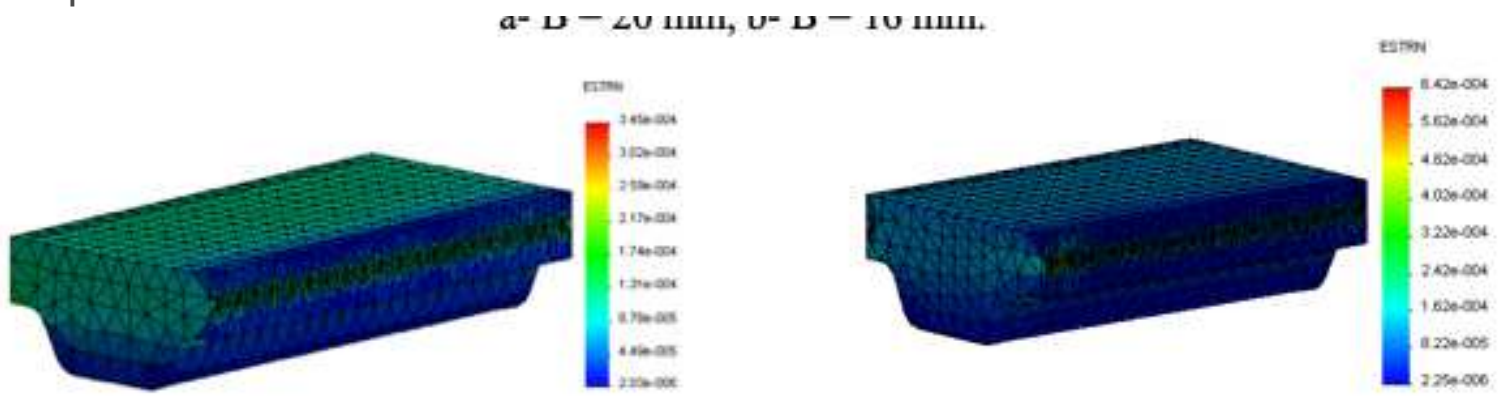


The deformations of the tooth of a belt AT10 for a tensile force of $100 \mathrm{~N}$ : $\mathrm{a}-\mathrm{B}=20 \mathrm{~mm}, \mathrm{~b}-\mathrm{B}=16 \mathrm{~mm}$.
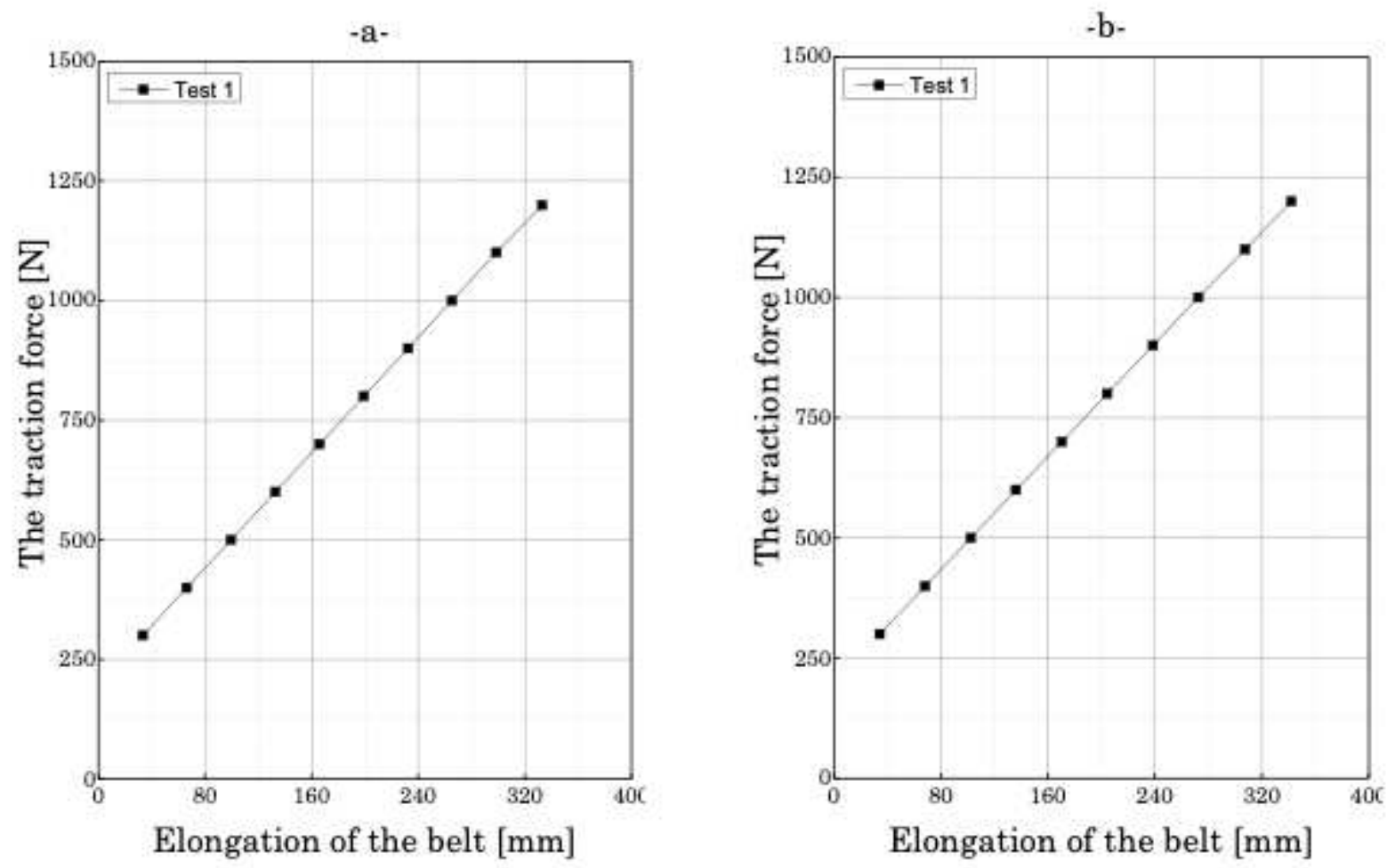

Figure 7

The simulation variation of the traction effort with respect to the elongation: $\mathrm{a}$ - width $16 \mathrm{~mm}, \mathrm{~b}$ - width 20 $\mathrm{mm}$ 


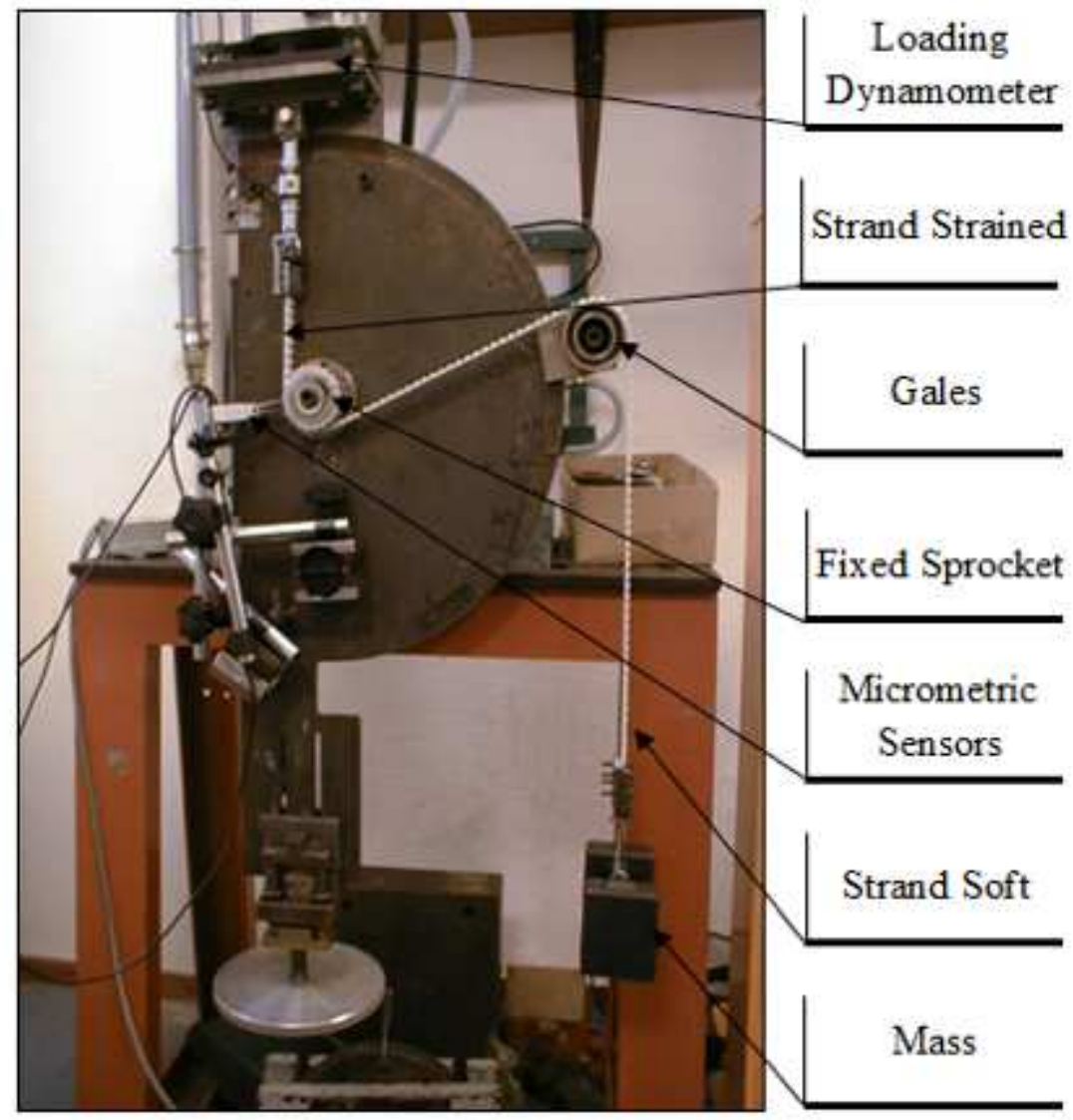

Figure 8

Device for measuring the stiffness of the tooth of the belt. 

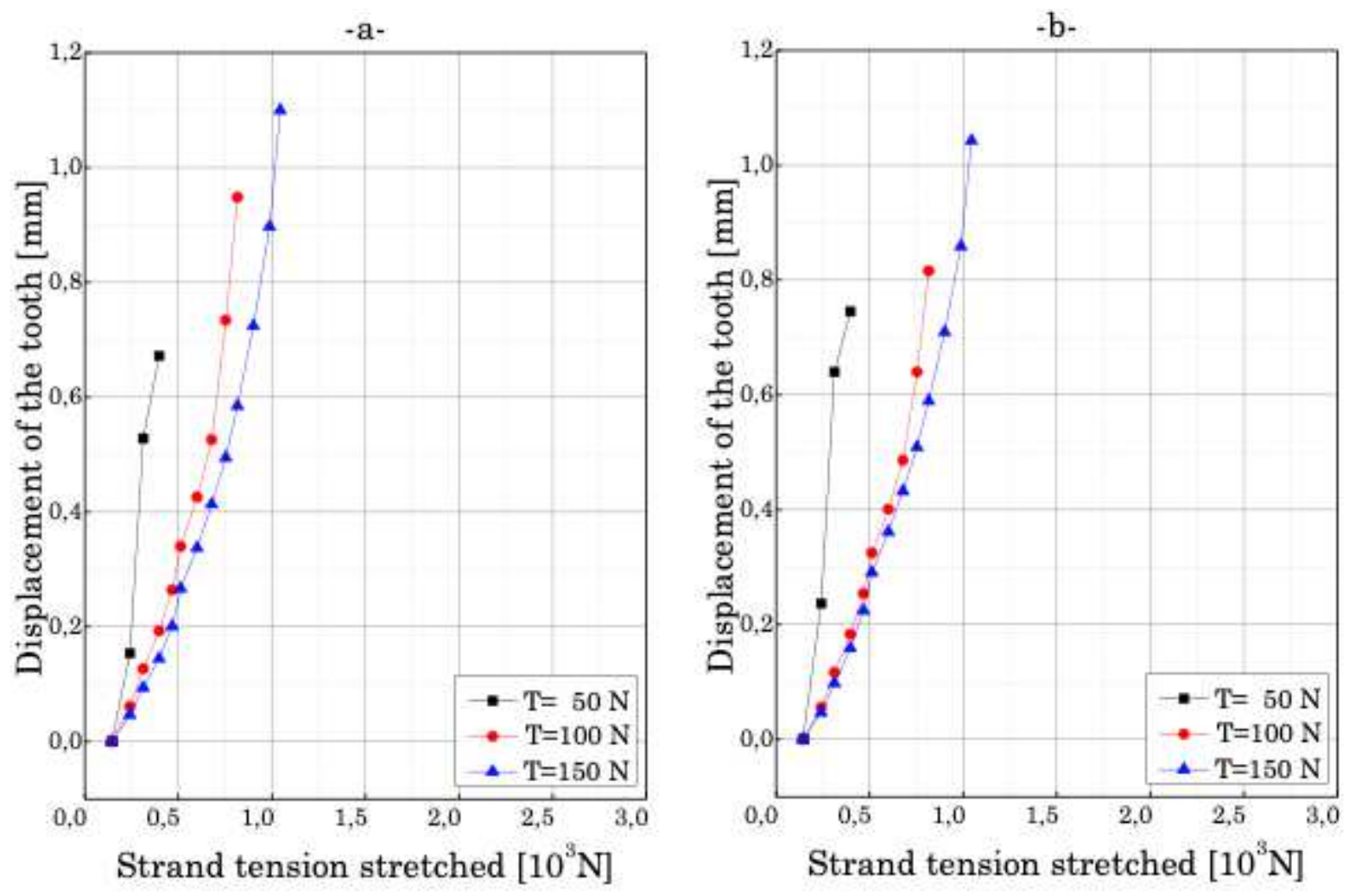

Figure 9

Variation of the tension of the tensioned strand as a function of the displacement of the tooth for 4 contact teeth between pulley-belt of B $=16 \mathrm{~mm}$ : a-Sensor 1 and b-Sensor 2
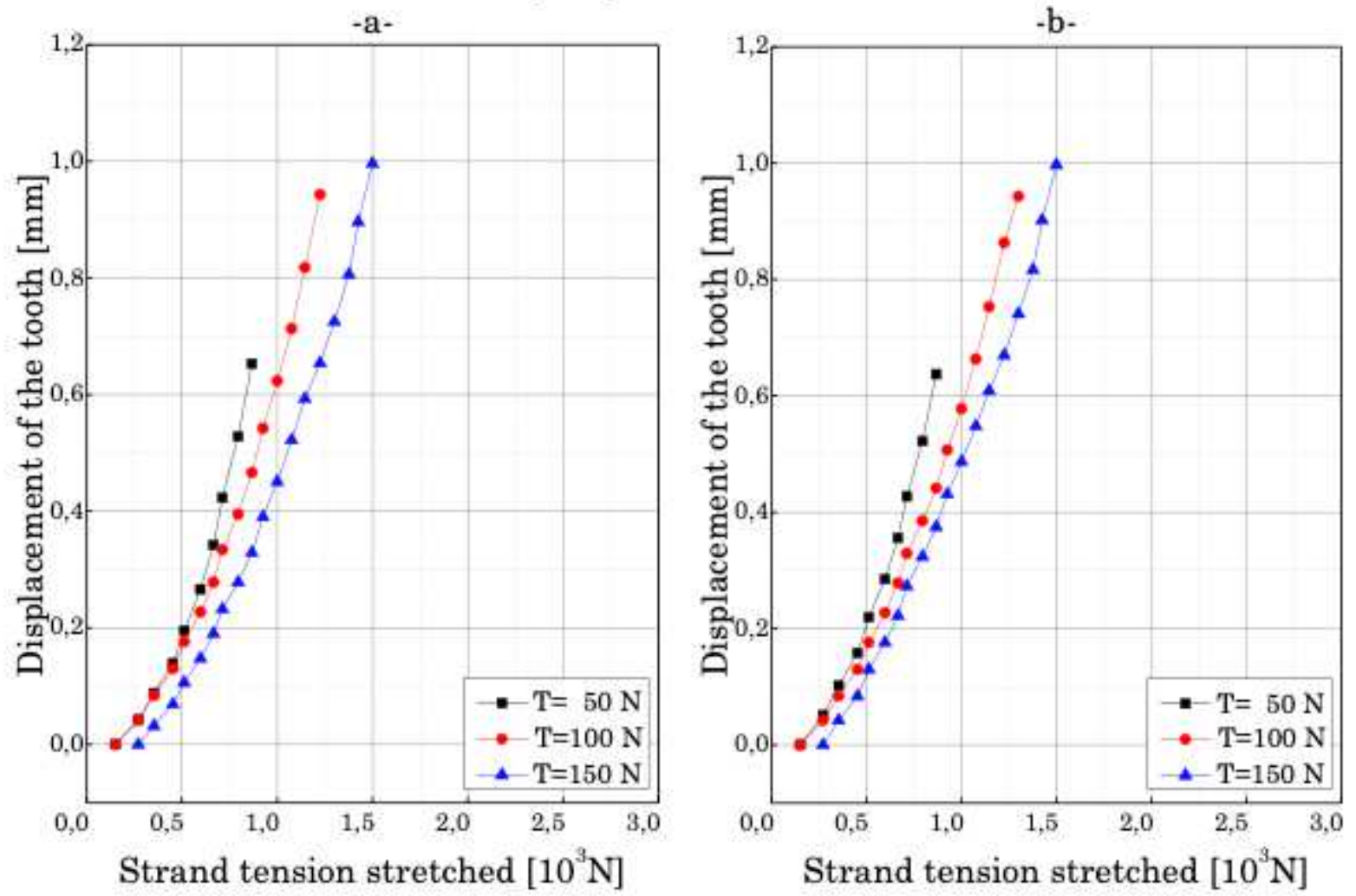
Figure 10

Variation of the tension of the tensioned strand as a function of the displacement of the tooth for 6 contact teeth between pulley-belt of $B=16 \mathrm{~mm}$ : a-Sensor 1 and $b$-Sensor 2 .
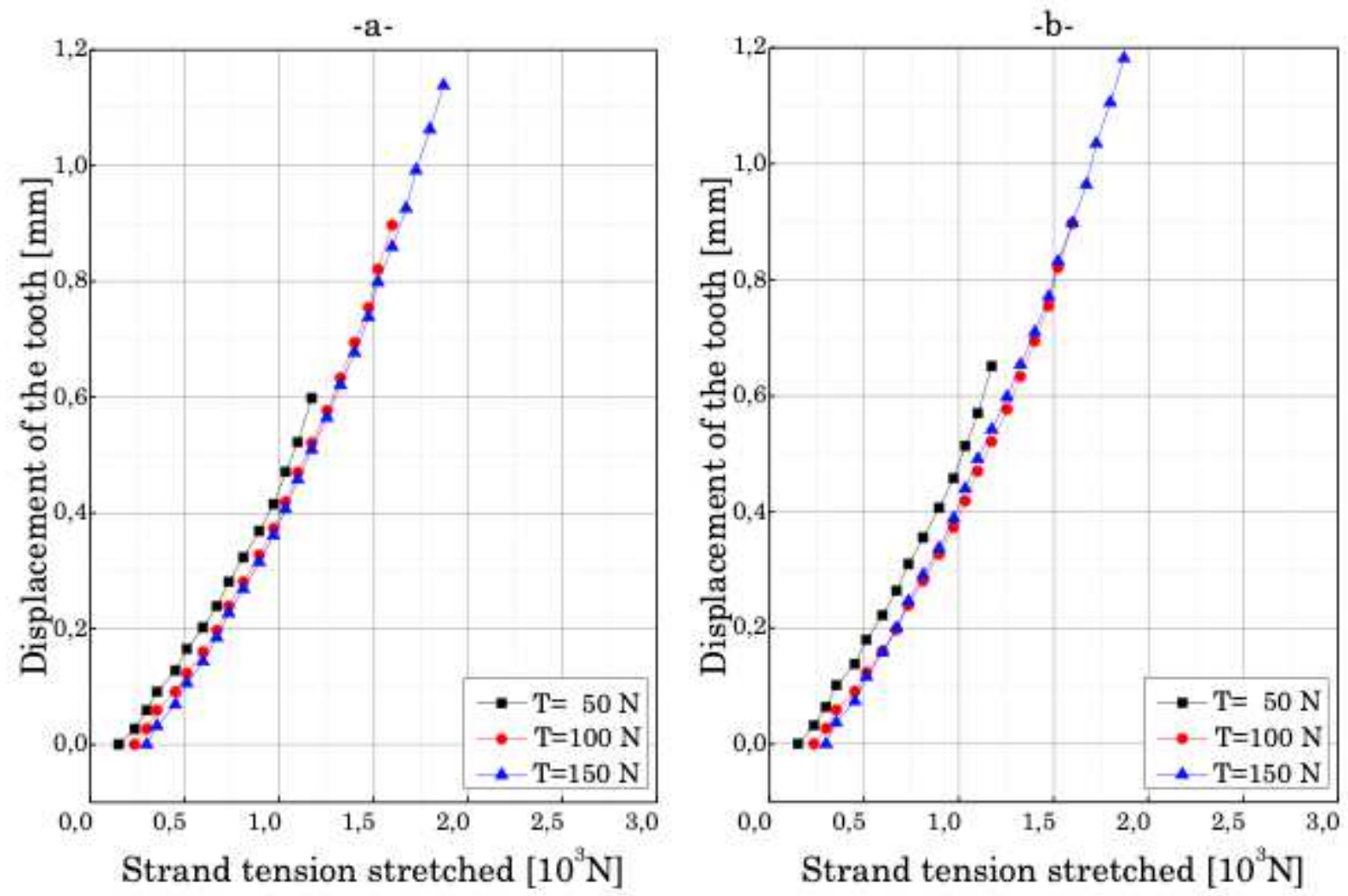

\section{Figure 11}

Variation of the tension of the tensioned strand as a function of the displacement of the tooth for 8 contact teeth between pulley-belt of $B=16 \mathrm{~mm}$ : a-Sensor 1 and b-Sensor 2 . 

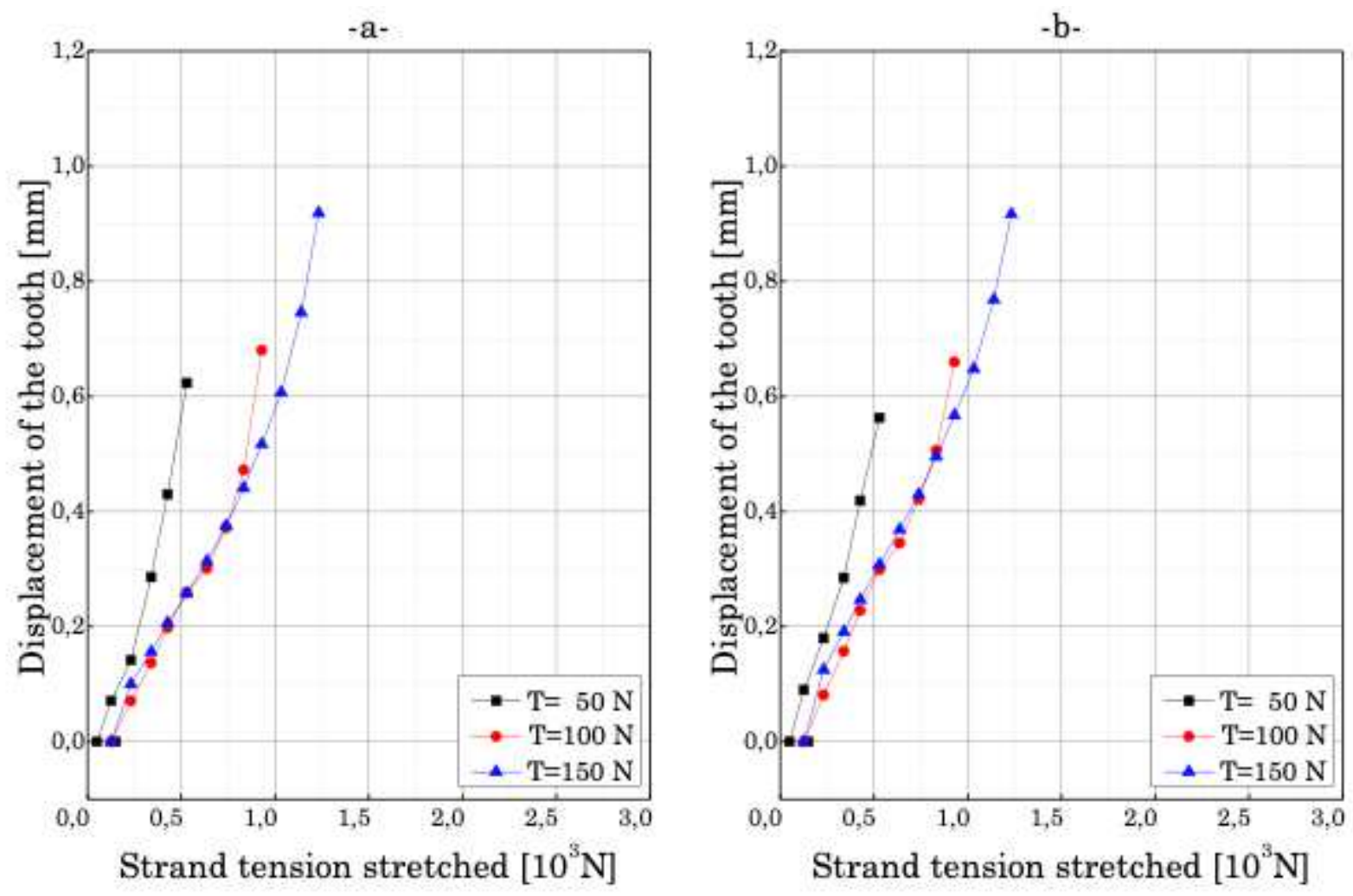

\section{Figure 12}

Variation of the tension of the tensioned strand as a function of the displacement of the tooth for 4 contact teeth between pulley-belt of $B=20 \mathrm{~mm}$ : a-Sensor 1 and b-Sensor 2 .
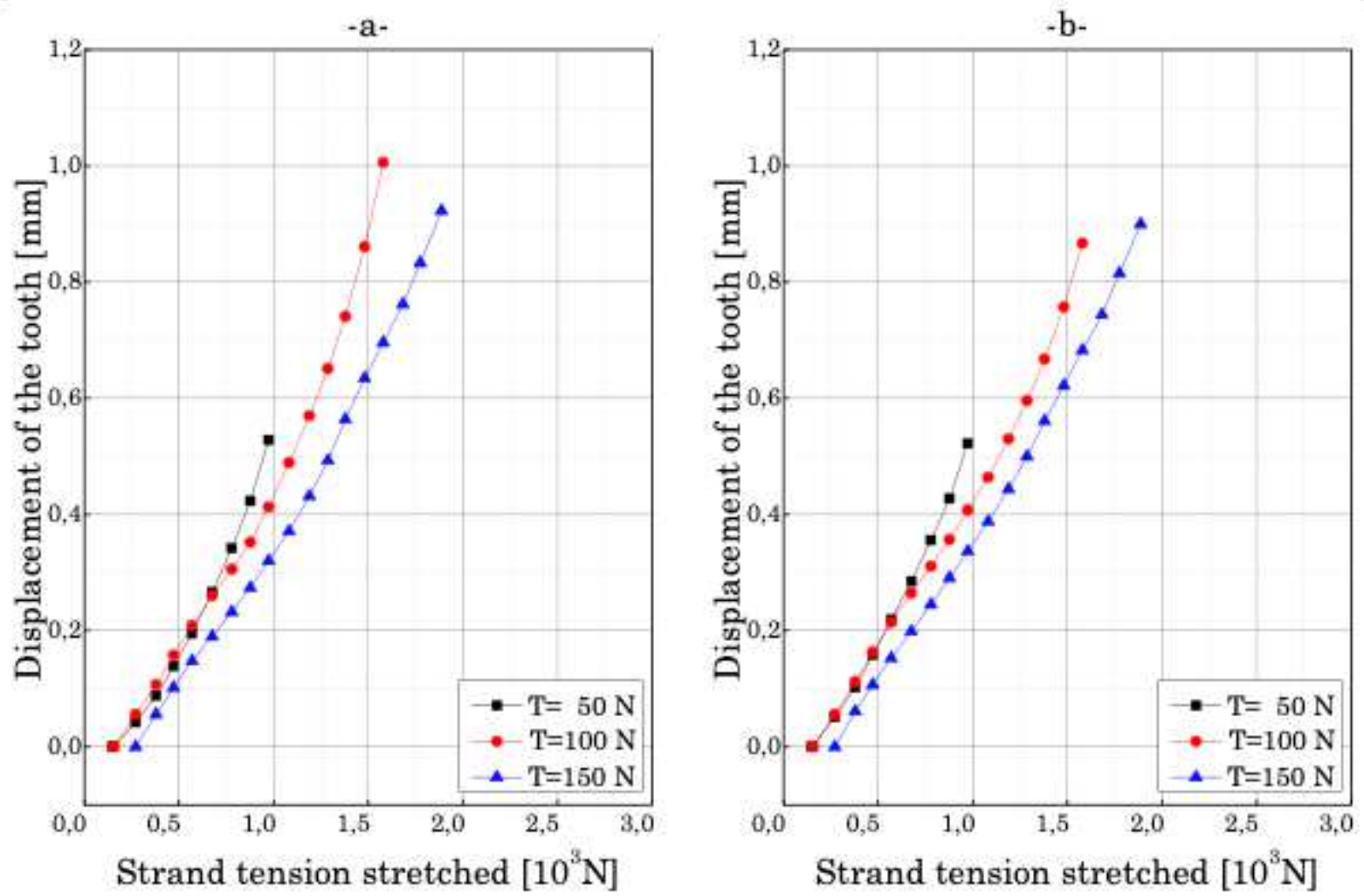
Figure 13

Variation of the tension of the tensioned strand as a function of the displacement of the tooth for 6 contact teeth between pulley-belt of $B=20 \mathrm{~mm}$ : a-Sensor 1 and b-Sensor 2 .

$-\mathrm{a}-$

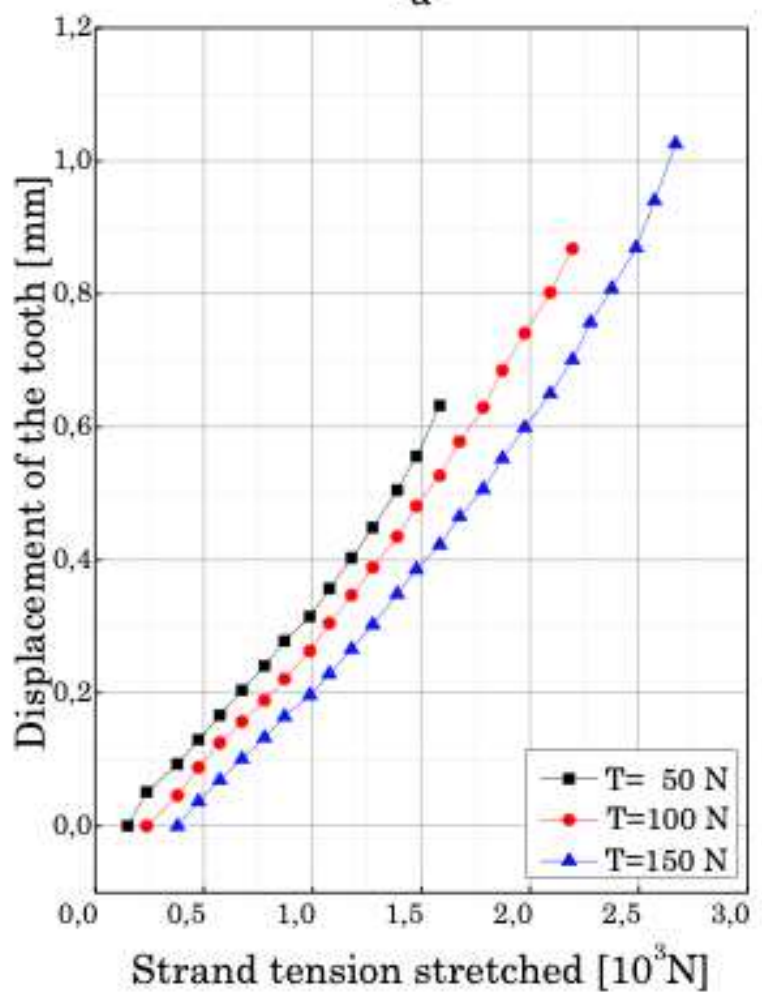

-b-

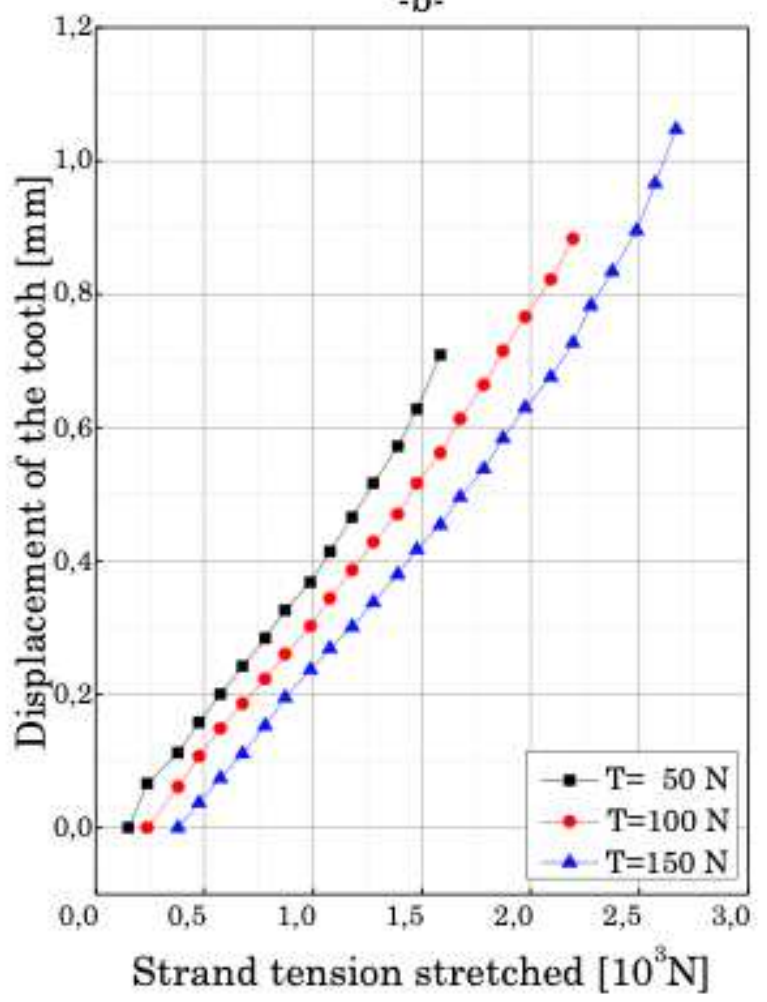

\section{Figure 14}

Variation of the tension of the tensioned strand as a function of the displacement of the tooth for 8 contact teeth between pulley-belt of $B=20 \mathrm{~mm}$ : a-Sensor 1 and b-Sensor 2 . 
$-\mathrm{a}-$

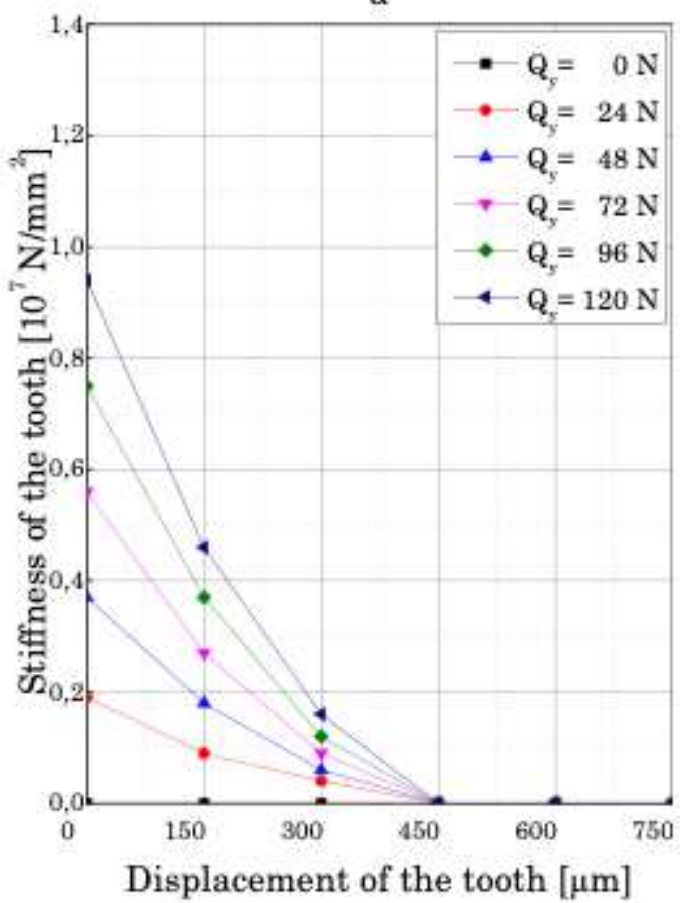

-b-

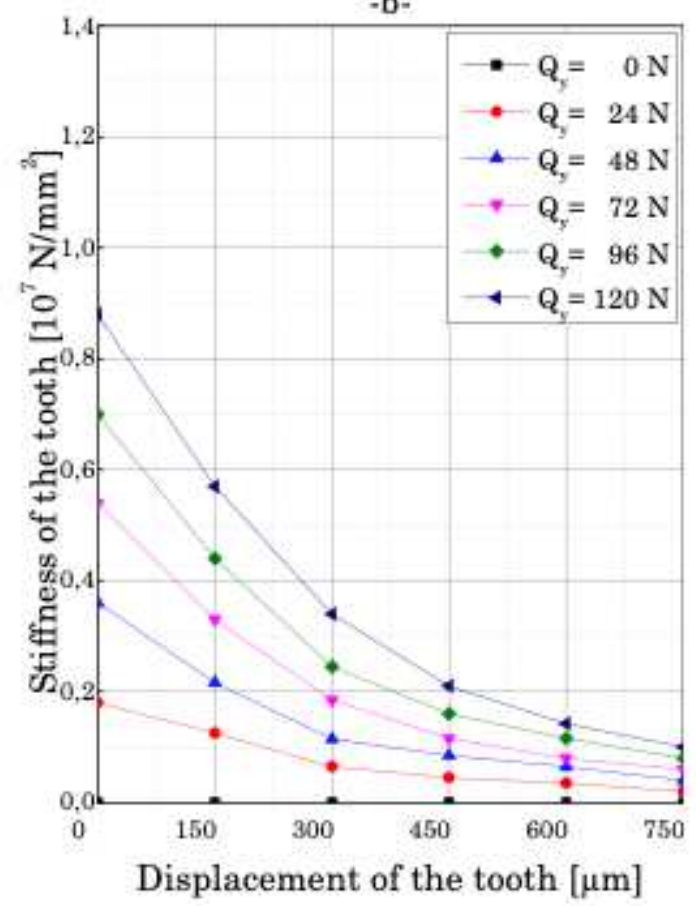

\section{Figure 15}

The variation of the tangential stiffness as a function of the displacement of the tooth and the load囚 Q -y: $\mathrm{a}-\mathrm{B}=16 \mathrm{~mm}, \mathrm{~b}-\mathrm{B}=20 \mathrm{~mm}$.
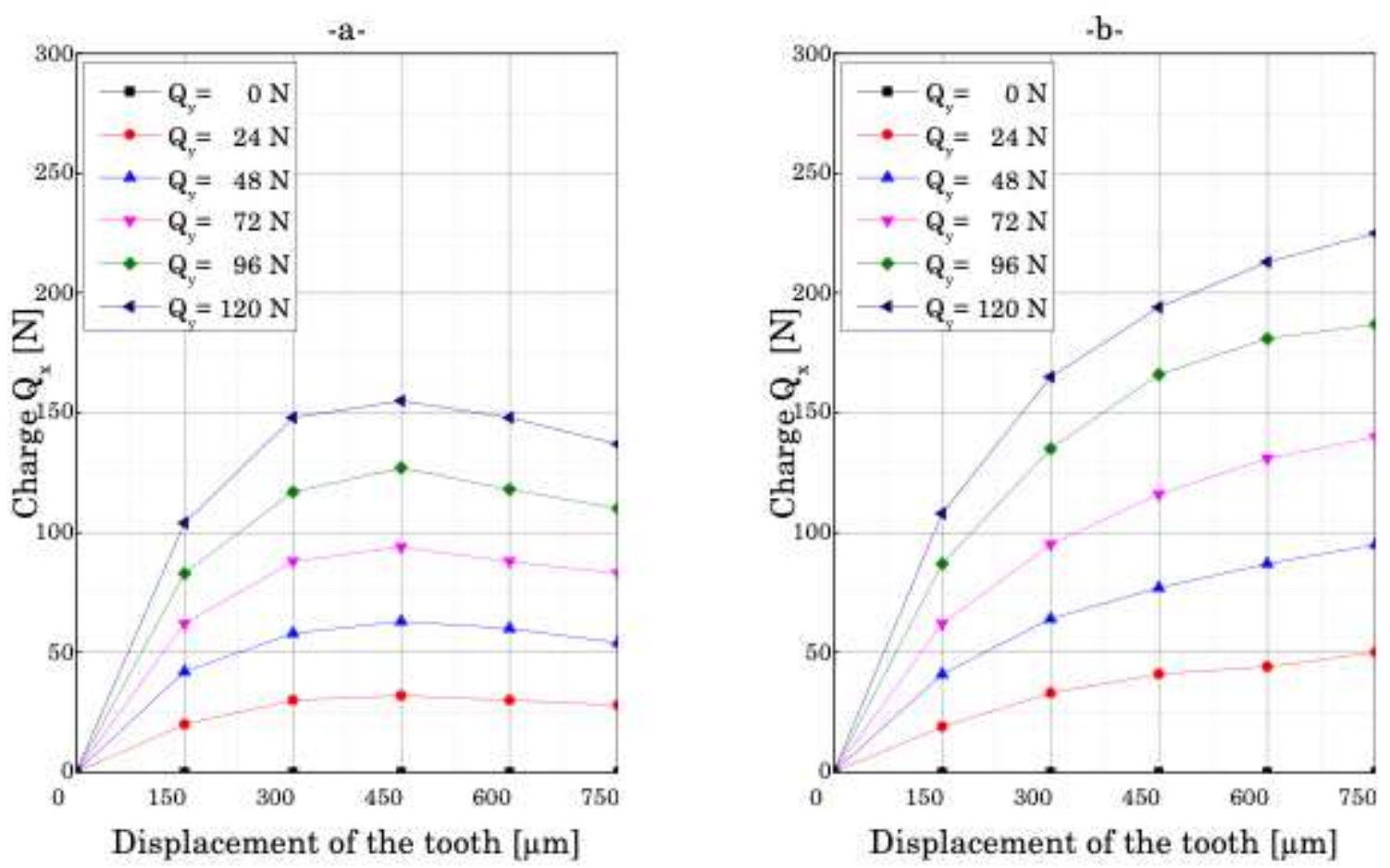

\section{Figure 16}

The variation of the tangential load $\mathbb{Q} \mathbb{Q} \_\mathrm{x}$ of a tooth as a function of the displacement of the tooth $\mathrm{u}$ and the load》 QQ_y: $a-B=16 \mathrm{~mm}, b-B=20 \mathrm{~mm}$. 

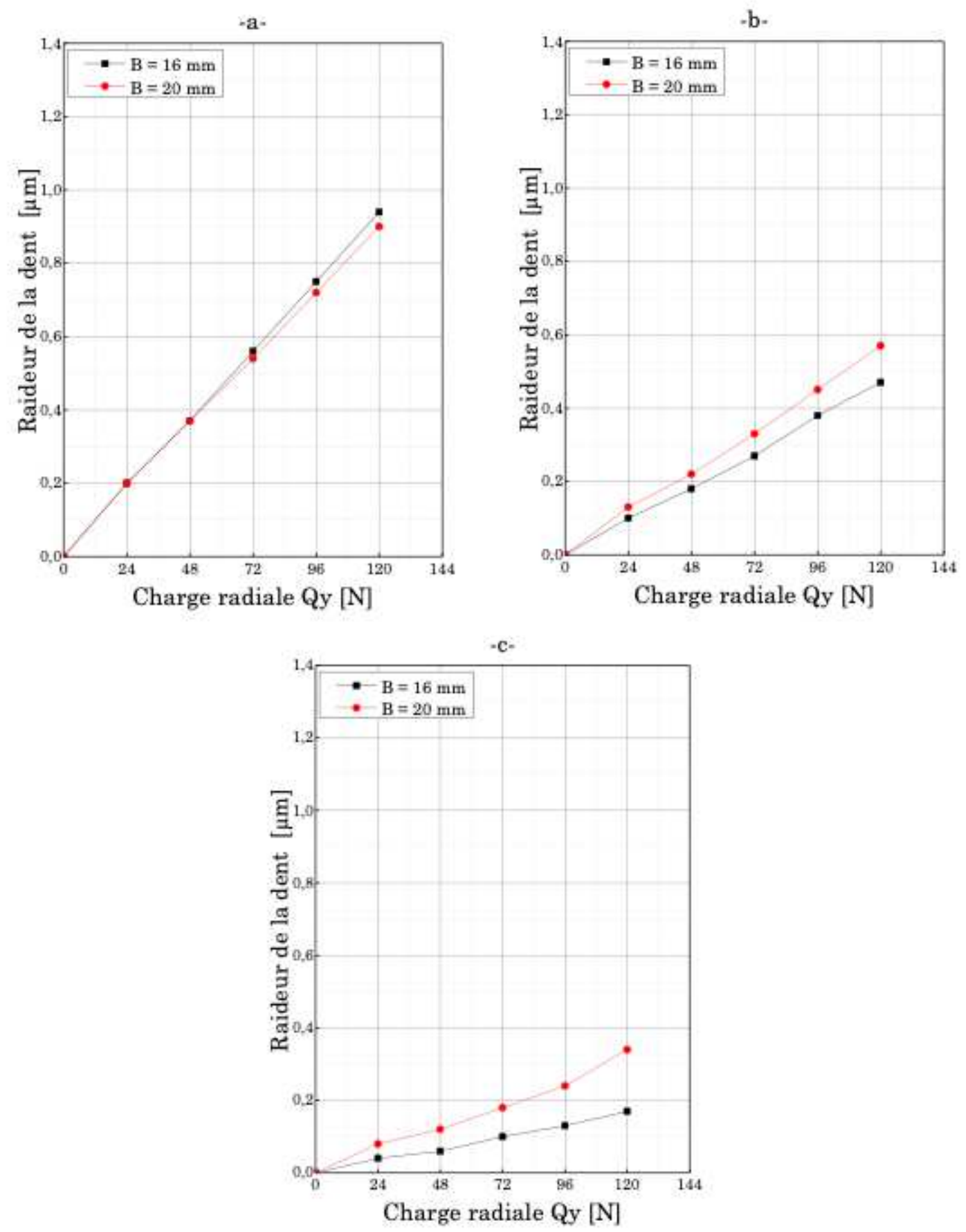

Figure 17

The variation of the tangential stiffness of the tooth of the two belts AT10 as a function of the load》 QD _y: $a-u=0 \mu \mathrm{m}, \mathrm{b}-\mathrm{u}=150 \mu \mathrm{m}, \mathrm{c}-\mathrm{u}=300 \mu \mathrm{m}$. 